the young at birth. Some may say, "Well, what is wrong with this, since this is what we believe in?" Only this, that others have glimpsed, at least with the inward eye, the vision of the uncrippled, their limbs intact and in no need of mending, running free and joyously again.

If we believe in prevention at all, our task today is surely not to conform or reinforce conformity to this dreadful doctrine but instead to question what is the validity of the source of authority for our present attitudes to sexuality, remembering always that other societies in the past have not been less noble or less civilised on a different, more humanistic basis.

NoRMan ChISHOLM

London NW3

\section{Acute renal failure due to polymyositis}

SIR,-Acute myolysis is a rare presentation of polymyositis and the short report by $\mathrm{Dr}$ Marion Sloan and others describing a case of acute renal failure due to polymyositis (3 June, p 1457) merits certain comments.

By polymyositis we usually mean a subacute, progressive muscle disease of unknown aetiology which does seem to respond to steroids, though the evidence for this is by no means concrete. ${ }^{1}$ Myoglobinuria, visible to the naked eye, is rare despite the quite frequent occurrence of immunologically detectable myoglobinaemia. ${ }^{2}$ Episodes of acute self-limiting myolysis with varying degrees of renal impairment are a feature of the rhabdomyolysis-myoglobinuria syndrome and the differential diagnosis which this clinical label implies is rapidly expanding. ${ }^{3}$

Before accepting the diagnosis as polymyositis, I would like to know how widespread the inflammatory cell infiltrate on biopsy was and whether the search for other possible aetiological factors was carried beyond those stated in the report.

J WADE

Department of Neurology

North Staffordshire Royal Infirmary,

' Bohan, A, and Peter, J B, New England fournal of Medicine, 1975, 292, 344.

${ }^{2}$ Kagen, L J, Fournal of the American Medical Association, 1977, 237, 1448 .

North America, and Penn, A S, Medical Clinics of

***We sent a copy of this letter to Dr Sloan and her colleagues, whose reply is printed

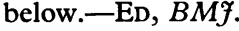

SIR,-Dr Wade raises an interesting and challenging point.

The biopsy specimen contained a mild mononuclear infiltrate related to the necrotic type I and type II fibres. There was an accumulation of lymphocytes allotted to one small vessel.

In addition to the aetiological factors detailed in the report, muscle biopsy myophosphorylase activity was normal. Stool culture revealed no cytopathic agent. Studies for leptospira were negative. There was no history of any recent drug ingestion. There were no other features to suggest the rhabdomyolysis-myoglobulinuria syndrome.

While recognising the comments in Dr Wade's letter, we feel that the diagnosis is that of polymyositis as four of the five criteria suggested by Bohan and Peter ${ }^{1}$ were satisfied, namely: (1) symmetrical weakness of the limb girdle muscles and anterior neck flexors progressing over weeks; (2) muscle biopsy evidence of necrosis of type I and type II fibres, phagocytosis regeneration with basophilia, variation in fibre size, and an in flammatory exudate related to necrotic fibres and blood vessels; (3) elevation in serum of skeletal muscle enzymes; and (4) electromyography showing irritability to needleprovocation at rest, with some myotonic potentials and patchy fibrillation activity. During attempts at contraction, many brief (less than $2 \mathrm{~ms}$ ) and polyphasic motor unit potentials were encountered.

MARION E SLOAN A J Franks

K A EXLEY

St James's University Hospital,

A M Davison Bohan, A, and Peter, J B, New England fournal of
Medicine, 1975, 292, 344.

\section{Medicine and the media}

SIR,-I was extremely surprised that a contributor to "Medicine and the media" (5 August, p 426) should have given credence to the newspapers in connection with the socalled test-tube baby. In Oldham we have been amused but also irritated by the spectacle of many journalists busy fertilising rumours and implanting them in each other's news papers, whose reports had very little to do with the real facts. It is true that the Brown family have a contract for their personal story which, if they manage to fulfil the conditions during the next year, will bring them in considerably less than $£ 100000$. There is no $£ 325000$. Several newspapers did make approaches offering very large sums of money for exclusive medical and scientific information about this birth. These were looked at in the hope that they might have afforded the opportunity to provide money for a suitable clinic for the work to continue. However, the conditions and exclusivity required were so impossible that all the offers, which severa newspapers were trying to better, were refused.

A much more disturbing and sinister aspect of this whole incident is the fact that the privacy of hospital records has been ruthlessly invaded and a number of names and addresses of patients who have been in hospita under my care have been obtained by newspaper reporters. Several of these patients have been approached by the reporters for their story. This means that the security of hospital records is very easily penetrated and thi unpleasant fact probably applies to all medica records throughout the country. Surely the medical profession must be alerted about this and protests must be made at the highest level to curb this kind of invasion of privacy. Otherwise no single person in this country can be sure of the confidential nature of the doctor-patient relationship.

It is hoped that the future of the Brown child will be one monitored by the medica profession, and that she will be spared the ordeal of overexposure by the media.

Oldham and District

Patrick Steptoe

General Hospita

General Hospit
Oldham, Lancs

\section{Misdiagnosis of amoebiasis}

SIR,-I write to congratulate $\mathrm{Dr} \mathrm{T} \mathrm{H}$ Foley and his colleagues (5 August, $p$ 428) for their public-spirited letter in drawing attention to a diagnostic pitfall in relation to a fatal case of amoebiasis, a condition which normally responds to medicinal treatment. I would further like to offer congratulations to you for a leading article (5 August, p 379) which puts foward some very practical suggestions to avoid such hazards in the future. This illustrates the importance of the initiative recently taken by the Royal College of Physicians of London in setting up a "medica services study group" under Sir Cyril Clarke and Dr George Whitfield. Valuable lessons can so often be learned from the dispassionate study of deaths in younger people. It is most encouraging to see this responsible lead being given by the royal college, the $B M F$, and individual doctors.

The diagnostic pitfall between ulcerative colitis and amoebiasis is indeed a very real one. May I add one clinical point? In any patient with ulcerative colitis who does no respond to corticosteroids the diagnosis must be quickly reviewed. Corticosteroids indeed are a very dangerous treatment for amoebiasis.

London W

F AVERY JONES

\section{Communication in hospital}

SIR,-Doctors are often blamed, frequently fairly, for not talking - as has again been shown by the excellent study of Maureen Reynolds (24 June, p 1673). An architect told me that we were the only profession with whom you cannot talk. If he planned a house for his doctor he would give him details, but neither his general practitioner nor other doctors spoke to him about his illness. No doubt a surveyor would explain dry rot, and my accountant certainly talks, though I prefer to leave myself in his hands and not to hear much about income tax, like some patients about their disease. However, the language problem in most other professions is trifling compared with the need to translate medical jargon into the vernacular and the sensitivity needed when dealing with the sick.

Today more patients want to know and are told what they want to know by the media. "They told me nothing" is a cliché, often though not always true. Asking the patient to write down questions-in addition to discussion at the bedside-helps to avoid this. The list is produced at the next round; questions may concern simple practical points, easily overlooked on a formal round. Also feedback can be got by asking the patient what he has learnt about the illness and its treatment; so often information is quickly forgotten. Handouts help and could be used more. For example, one about coronary infarction with reassurance and practical guidance can be given to the patient, who will discuss it with his spouse and, if necessary, produce it later to clear up any doubts.

Conflicting information commonly confuses. Different doctors are seen on each visit either at hospital or in group practice, and different diagnoses are given for the same condition-for example, pain in the shoulder may be called rheumatism, neuritis, or arthritis-and contrary advice may be proffered. This can be avoided by writing 